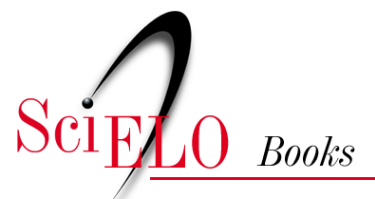

\begin{abstract}
Anexos
Comissão Nacional sobre Determinantes Sociais da Saúde
\end{abstract}

COMISSÃO NACIONAL SOBRE DETERMINANTES SOCIAIS DA SAÚDE. Anexos. In: $A s$ causas sociais das iniqüidades em saúde no Brasil [online]. Rio de Janeiro: Editora FIOCRUZ, 2008, pp. 175-191. ISBN: 978-85-7541-591-7. Available from: doi: 10.7476/9788575415917.0007. Also available in ePUB from: http://books.scielo.org/id/bwb4z/epub/comissao-9788575415917.epub.

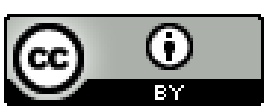

All the contents of this work, except where otherwise noted, is licensed under a Creative Commons Attribution $\underline{4.0 \text { International license. }}$

Todo o conteúdo deste trabalho, exceto quando houver ressalva, é publicado sob a licença Creative Commons Atribição 4.0. 


\section{ANEXOS}

\section{Anexo I}

\section{RelatóRio de AtividADEs dA CNDSS}

As atividades desenvolvidas pela CNDSS estiveram organizadas em cinco linhas de ação, que buscaram responder aos objetivos e atribuições definidos no Decreto Presidencial que a criou, em 13 de março de 2006. No âmbito de cada uma destas linhas, foram desenvolvidas diversas atividades, que contaram com a participação de especialistas, profissionais e participantes de instituições colaboradoras, além de membros da Comissão.

A Comissão foi apoiada técnica e operacionalmente por uma Secretaria Técnica (ST), instalada na Fiocruz. A ST esteve integrada por Alberto Pellegrini Filho e Alice Branco, com o apoio administrativo de Fátima Correa. Contou também com o apoio de diversos profissionais e setores da Fiocruz, para o desenvolvimento de suas atribuições e para a administração técnica e financeira dos projetos desenvolvidos no âmbito das diversas linhas de ação. Maiores detalhes sobre estas linhas de ação e atividades correspondentes podem ser encontrados em <www.determinantes.fiocruz.br $>$.

A primeira linha de ação se refere à Produção e Disseminação de Conhecimentos e Informações, que teve por objetivo produzir conhecimentos e informações sobre as relações entre os determinantes sociais e a situação de saúde, particularmente as iniqüidades em saúde, com vistas a fundamentar políticas e programas. No âmbito desta linha de ação, foi lançado um edital de pesquisa, em junho de 2006, em parceria com o Ministério da Saúde e o Conselho Nacional de Desenvolvimento Científico e Tecnológico (CNPq). Seu objetivo foi apoiar o desenvolvimento de projetos sobre DSS, incluindo avaliação de intervenções sobre estes determinantes. Em setembro de 2006, foram selecionados 21 projetos (listados no anexo Ia), totalizando cerca de três milhões de reais. Os projetos tiveram início em fevereiro/março de 2007, tendo sido criada uma comunidade virtual, integrada pelos pesquisadores envolvidos, além de gestores e outros convidados. A criação desta comunidade virtual teve por objetivo acompanhar o andamento dos projetos e identificar eventuais implicações de seus resultados intermediários para políticas e programas. Aspectos metodológicos de interesse comum e temas relacionados aos DSS são também objeto de discussões no âmbito desta comunidade virtual.

Outro projeto incluído nesta linha de ação se refere à compilação, revisão e análise de sistemas de informação, com o objetivo de facilitar o acesso ao acervo de dados, informações e indicadores relativos a DSS, produzidos no Brasil, por distintas fontes. Foi feita a identificação dos sistemas de informação e a organização do acervo selecionado, de forma a facilitar o acesso ao público não especialista e a análise de seu potencial de uso. Os acervos serão colocados à disposição do 
público no Portal sobre Determinantes Sociais da Saúde, que será lançado no primeiro semestre de 2008 e terá o mesmo endereço atualmente utilizado para a página da CNDSS (www.determinantes. fiocruz.br). Este acervo deverá ser permanentemente atualizado, acompanhando as alterações dos sistemas de informação.

Ainda no âmbito desta primeira linha de ação, foi realizado em Brasília, em setembro de 2006, um Seminário Metodológico sobre Avaliação de Intervenções para Combate às Iniqüidades em Saúde. O seminário teve o objetivo de revisar o "estado da arte" das metodologias de avaliação existentes, assim como a experiência nacional e internacional em sua utilização. Contou com a participação de especialistas nacionais e internacionais, membros da CNDSS, membros do Grupo de Trabalho intersetorial (ver linha de ação Políticas e Programas) e outros convidados. As apresentações realizadas durante o seminário, assim como um relatório das principais discussões e recomendações, podem ser encontrados na página da CNDSS.

A segunda linha de ação se refere a Políticas e Programas e teve por objetivo promover, coordenar e avaliar políticas, programas e intervenções governamentais e não governamentais sobre os DSS, realizadas em nível local, regional e nacional. A principal atividade relacionada a esta linha de atuação foi dar apoio técnico e operacional ao Grupo de Trabalho (GT), estabelecido pelo Decreto Presidencial que criou a CNDSS e integrado por representantes de diversos níveis da administração pública. O GT, embora criado em março de 2006, só foi formalmente estabelecido em 18 de dezembro do mesmo ano, por meio da Portaria no 3.178 do Ministro da Saúde. Através de reuniões e outros meios de comunicação, criaram-se oportunidades para intercâmbio de informações e discussão de temas de interesse comum entre seus membros, mas o potencial do GT como instrumento de coordenação das ações das diversas instituições que o integram não foi plenamente realizado. A revisão e análise de políticas e programas em curso incluída neste Relatório também se inscreve nesta linha de ação.

A CNDSS teve contribuição decisiva na elaboração do Protocolo de Intenções, assinado em setembro de 2007, entre o Ministério da Saúde, Fundação Oswaldo Cruz, Conass e Conasems para o fortalecimento de ações intersetoriais de promoção da saúde nas esferas estadual e municipal. Mais especificamente, este Protocolo de Intenções e os projetos que o integram têm como objetivos:

- capacitar gestores e tomadores de decisão, em âmbito municipal e estadual, para promover e executar ações setoriais e intersetoriais de promoção da saúde;

- facilitar o acesso a gestores e lideranças comunitárias, a dados, informações e literatura, que respondam a suas necessidades e demandas para promoção de intervenções sobre os DSS;

- facilitar, aos gestores de âmbito municipal e estadual, espaços e oportunidades de intercâmbio e troca de experiências sobre intervenções, visando a promoção da saúde e o combate às iniqüidades;

- proporcionar metodologias e mecanismos, em âmbito municipal e estadual, para a definição e execução de políticas e programas intersetoriais de promoção da saúde;

- promover a produção e disseminação de conhecimento original sobre iniqüidades em saúde e, particularmente, sobre desenho e avaliação de intervenções sobre seus determinantes sociais. 
A terceira linha de ação se refere à Mobilização da Sociedade Civil e teve por objetivo chamar a atenção de diversos setores da sociedade sobre a importância dos DSS e sobre as possibilidades de atuação sobre eles. Esse chamado à tomada de consciência, em especial sobre a gravidade das iniqüidades em saúde, foi feito por meio da participação da Secretaria Técnica e membros da Comissão em diversos congressos, conferências, cursos, painéis e mesas-redondas, organizados por entidades científicas, profissionais de saúde, gestores, ONGs e outras entidades. Foram também utilizados diversos meios de comunicação massiva como a televisão, inclusive programas do Canal Saúde produzidos pela Fiocruz, e uma série de matérias e artigos publicados em revistas de ampla circulação como a revista Radis e jornais diários. Artigos científicos foram também publicados em revistas como os Cadernos de Saúde Pública, Physis e outras, para divulgação da CNDSS e para promoção do debate sobre os DSS entre os profissionais de saúde pública.

No âmbito desta linha, destaca-se a realização de um fórum de entidades da sociedade civil em Brasília, em abril de 2007, para explorar oportunidades de atuação conjunta em favor da eqüidade em saúde. Em abril de 2008, foi realizado, em Porto Alegre, o Fórum Saúde e Comunicação, com a participação de mais de 500 profissionais de saúde e dos meios de comunicação, para discutir, desde suas diferentes perspectivas, conceitos, estratégias e experiências, visando fortalecer a comunicação para a promoção da saúde. Merece também destaque a elaboração, em agosto de 2006, de uma Carta Aberta assinada por todos os membros da CNDSS aos candidatos à Presidência da República (Anexo Ib), com o objetivo de promover o debate público de políticas e programas de governo relacionados aos determinantes sociais da saúde (DSS).

A quarta linha de ação corresponde à Construção e Manutenção de Portal sobre Determinantes Sociais da Saúde (www.determinantes.fiocruz.br). Além de registrar as atividades que foram desenvolvidas pela CNDSS, incluindo documentos e apresentações por ela produzidos, o Portal tem por objetivo coletar e registrar informações e conhecimentos sobre DSS disponíveis nos sistemas de informação e na literatura científica nacional e internacional, constituindo-se num espaço de referência para os interessados no tema. O Portal sobre DSS deve também se consolidar como um ambiente de interação entre diversos atores relacionados aos DSS, como pesquisadores, profissionais de saúde, gestores, membros de organizações da sociedade civil e público em geral. Com o término do mandato da CNDSS, o Portal será mantido e atualizado pelo Instituto de Comunicação e Informação Científica e Tecnológica da Fiocruz (Icict/Fiocruz).

A quinta linha de ação se refere à Cooperação Internacional, que inclui Cooperação com a Comissão sobre Determinantes Sociais da Saúde da OMS (CSDH) e com os países da América Latina, para promoção do enfoque de DSS em suas políticas de saúde e/ou criação de suas respectivas comissões nacionais. Com relação à cooperação com a Comissão da OMS, foram realizadas diversas atividades conjuntas de caráter técnico e, no que se refere à organização colaborativa de eventos, merecem destaque: 1) a realização da 6ª Reunião da CSDH em setembro de 2006, no Rio de Janeiro, conjuntamente com a $2^{\text {a }}$ Reunião da CNDSS; 2) a organização do $1^{\circ}$ Fórum de Consulta da Sociedade Civil dos países da América Latina, em abril de 2007, em Brasília, em colaboração com OEA, MS e OPS/OMS; 3) a reunião das Redes de Conhecimento (Knowledge Networks), em setembro de 2007, no Rio de Janeiro. 
Anexo I A

\begin{tabular}{|c|c|c|c|c|c|c|c|c|c|c|c|c|c|c|c|c|c|c|c|c|c|}
\hline 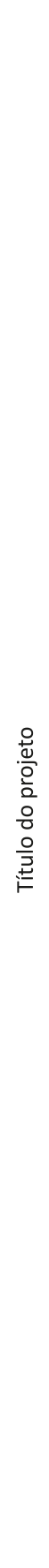 & 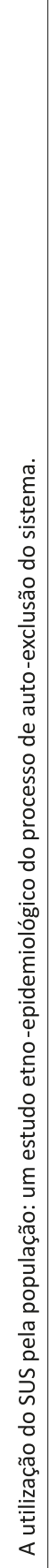 & 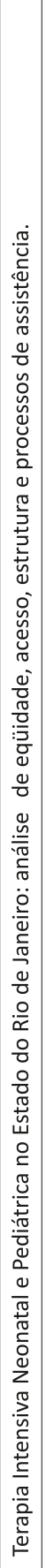 & 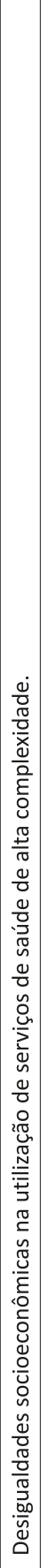 & 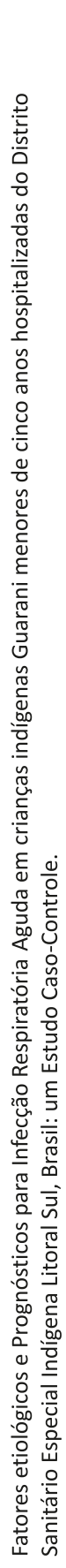 & 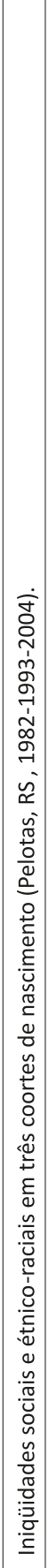 & 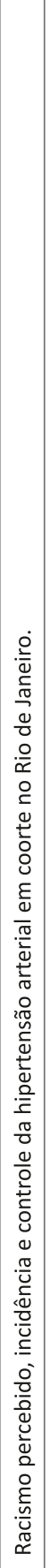 & 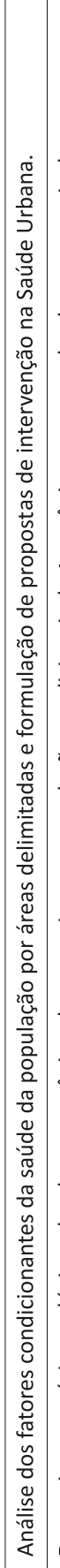 & 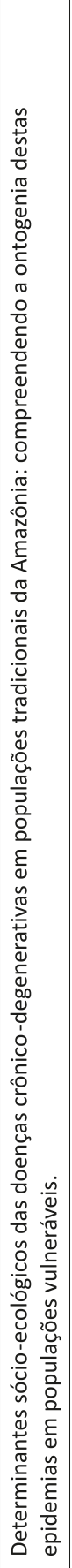 & 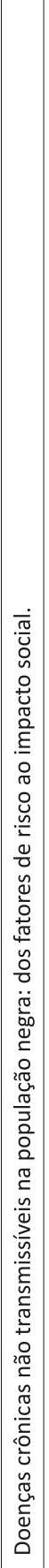 & 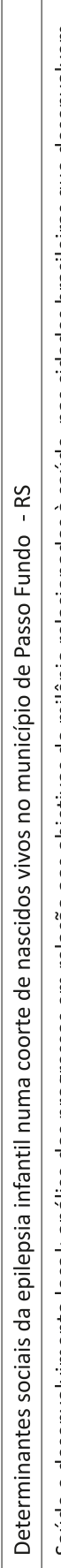 & 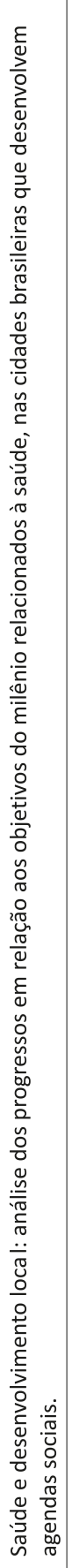 & 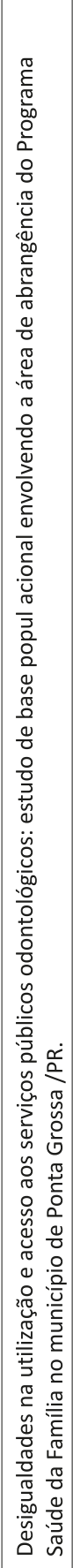 & 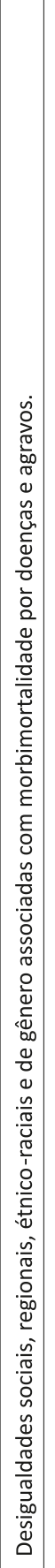 & 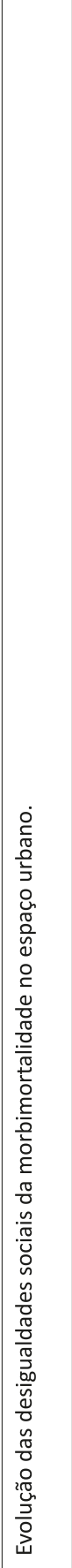 & 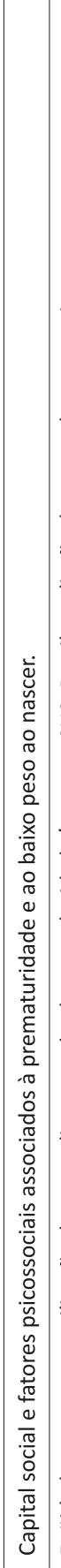 & 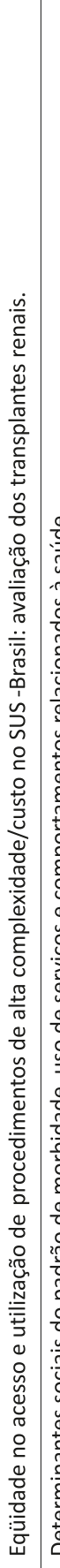 & 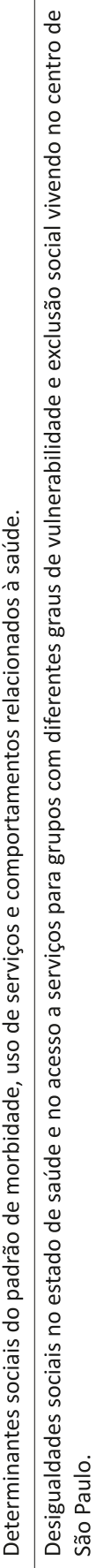 & 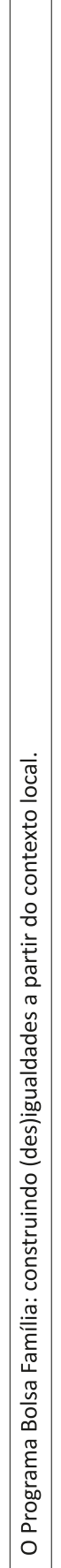 & 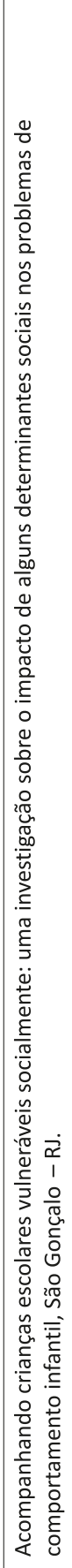 & 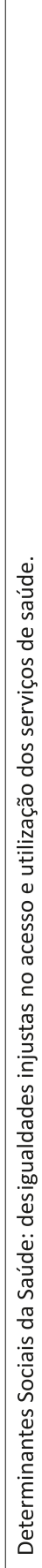 & 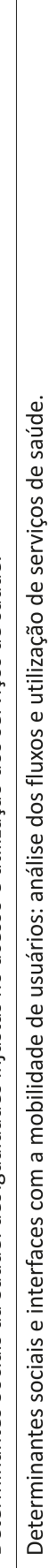 \\
\hline 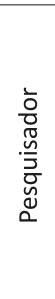 & 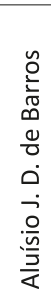 & 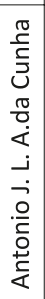 & 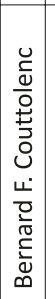 & 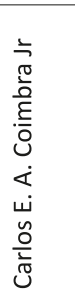 & 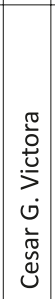 & 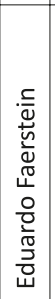 & 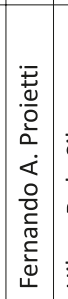 & 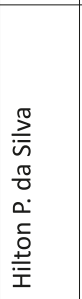 & 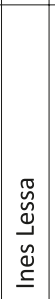 & 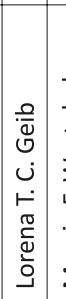 & 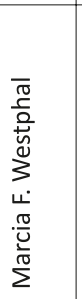 & 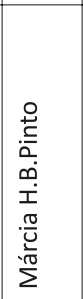 & 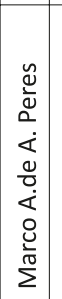 & 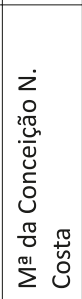 & 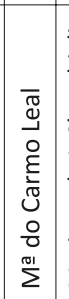 & 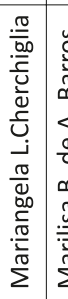 & 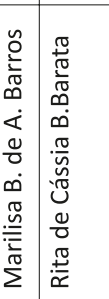 & 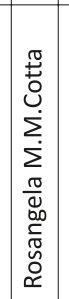 & 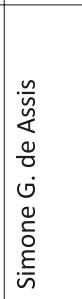 & 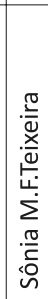 & 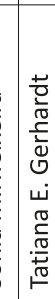 \\
\hline
\end{tabular}




\section{Anexo I B}

\section{Carta Aberta da Comissão Nacional sobre Determinantes Sociais da Saúde aos CANDidatos À PREsidênCIA dA República}

Agosto de 2006

Srs.(a) Candidatos(a) a Presidente do Brasil,

Nós, membros da Comissão Nacional sobre Determinantes Sociais da Saúde,

Preocupados com as enormes desigualdades em saúde no Brasil que, além de injustas, são evitáveis e desnecessárias;

Sabedores de que essas desigualdades são resultado do desemprego, da violência, da falta de perspectivas e das precárias condições de vida a que está submetida grande parte da população brasileira, acentuadas pelas dimensões de gênero e etnia;

Convencidos de que políticas públicas baseadas em informações confiáveis e com amplo apoio político dos diversos segmentos da sociedade brasileira podem reverter esse quadro, tal como ocorre em outros países com desenvolvimento econômico igual ou inferior ao nosso,

Instamos os Srs(a). Candidatos(a) à Presidência da República do Brasil a incluir em seus programas de governo ações concretas para a melhoria das condições de saúde, particularmente de promoção da eqüidade em saúde,

Que tenham por referência o conceito de saúde tal como a concebe a Organização Mundial da Saúde, como um estado de completo bem-estar físico, mental e social e não meramente a ausência de doença ou enfermidade,

Que cumpram o preceito constitucional de reconhecer a saúde como um "direito de todos e dever do Estado, garantido mediante políticas sociais e econômicas que visem à redução do risco de doença e outros agravos e ao acesso universal e igualitário às ações e serviços para sua promoção, proteção e recuperação",

Que contemplem os determinantes sociais da saúde em todos os seus níveis, incluindo:

- Políticas que favoreçam mudanças de comportamento para a redução de riscos e aumento da qualidade de vida mediante programas educativos, comunicação social, acesso facilitado a alimentos saudáveis, criação de espaços públicos para a prática de esportes e exercícios físicos, bem como proibição à propaganda do tabaco e do álcool em todas a suas formas;

- Políticas que favoreçam ações de promoção da saúde, da paz e da justiça social, buscando estreitar relações de solidariedade e confiança, construir redes de apoio e fortalecer a organização e participação das pessoas e das comunidades em ações coletivas para melhoria de suas condições de saúde e bem estar, especialmente dos grupos sociais vulneráveis; 
- Políticas que assegurem a melhoria das condições de vida da população, garantindo a todos o acesso à água limpa, esgoto, habitação adequada, ambientes de trabalho saudáveis, serviços de saúde e de educação de qualidade, superando abordagens setoriais fragmentadas e promovendo uma ação planejada e integrada dos diversos níveis da administração pública e

- Políticas macroeconômicas e de mercado de trabalho, de proteção ambiental e de promoção de uma cultura de paz e solidariedade que visem promover um desenvolvimento sustentável, reduzindo as desigualdades sociais e econômicas, as violências, a degradação ambiental e seus efeitos sobre a sociedade.

Estamos seguros de que um futuro governo que trate das questões de saúde sob o enfoque dos determinantes sociais, formulando e avaliando suas políticas em função do impacto sobre a qualidade de vida e a eqüidade e não apenas sobre a melhoria das médias dos indicadores de saúde, estará correspondendo plenamente aos anseios da população brasileira por um país mais justo e humano.

Paulo M. BusS - médico, presidente da Fundação Oswaldo Cruz, membro titular da Academia Nacional de Medicina, coordenador da Comissão;

Adib Jatene - médico, ex-professor da Universidade de São Paulo, ex-ministro da Saúde do Brasil, membro titular da Academia Nacional de Medicina;

Aloísio Teixeira - economista, reitor da Universidade Federal do Rio de Janeiro;

Cesar Victora - médico, professor de epidemiologia, Universidade Federal de Pelotas, membro titular da Academia Brasileira de Ciências;

Dalmo Dallari - advogado, professor de direito da Universidade de São Paulo, membro da Comissão Internacional de Juristas;

Eduardo Eugênio Gouvêa Vieira - empresário, presidente da Federação das Indústrias do Estado do Rio de Janeiro;

Elza Berquó - demógrafa, pesquisadora do Centro Brasileiro de Análise e Planejamento, membro titular da Academia Brasileira de Ciências;

Jaguar - cartunista;

Jairnilson Paim - médico, professor de planejamento de saúde da Universidade Federal da Bahia;

Lucélia Santos - atriz;

Moacyr Scliar - médico, escritor e membro da Academia Brasileira de Letras;

Roberto Smeraldi - ambientalista, diretor da Organização da Sociedade Civil de Interesse Público Amigos da Terra-Amazônia Brasileira;

Rubem César Fernandes - antropólogo, coordenador do Movimento Viva Rio;

Sandra de Sá - cantora;

Sônia Fleury - cientista política, professora de políticas públicas e de saúde da Fundação Getulio Vargas;

Zilda Arns - médica, coordenadora da Pastoral da Criança. 


\title{
Anexo II
}

\section{Decreto Presidencial oue criou a Comissão Nacional sobre Determinantes Sociais DA SAÚDE:}

\author{
Presidência da República \\ Casa Civil \\ Subchefia para Assuntos Jurídicos
}

DECRETO DE 13 DE MARÇO DE 2006

Institui, no âmbito do Ministério da Saúde, a Comissão sobre Determinantes Sociais da Saúde (CNDSS).

O PRESIDENTE DA REPÚBLICA, no uso da atribuição que lhe confere o art. 84, inciso VI, alínea "a", da Constituição,

\section{DECRETA:}

Art. $1^{\circ}$ Fica instituída, no âmbito do Ministério da Saúde, a Comissão Nacional sobre Determinantes Sociais da Saúde - CNDSS, com o objetivo de:

I - apoiar e articular a atuação do Poder Público, instituições de pesquisa e da sociedade civil sobre determinantes sociais relacionados à melhoria da saúde e redução das iniqüidades sanitárias;

II - promover modelos e práticas efetivas relacionadas aos determinantes sociais da saúde e voltados à inserção da eqüidade em saúde nas políticas de governo;

III - contribuir para a formulação e implementação de políticas, planos e programas de saúde baseados em intervenções sobre os determinantes sociais que condicionam o nível de saúde;

IV - organizar e gerar informações e conhecimentos voltados a informar políticas e ações sobre os determinantes sociais da saúde; e

V - mobilizar setores de governo e a sociedade civil para atuar na prevenção e solução dos efeitos negativos de determinantes sociais da saúde.

Art. $2^{\circ}$ A CNDSS será composta por dezessete membros, de livre escolha e designação pelo Ministro de Estado da Saúde, entre brasileiros de renomado conhecimento e liderança em temas da área da saúde e integrantes de instituições acadêmicas, de notável saber.

Art. $3^{\circ}$ Com vistas ao atendimento de seus objetivos, a CNDSS deverá:

I - reunir dados sobre intervenções eficazes e propor políticas relativas aos principais determinantes sociais, com ênfase nas populações de baixa renda;

II - articular redes de especialistas, líderes sociais e pesquisadores com vistas a reunir 
conhecimentos sobre intervenções e políticas efetivas para enfrentar os determinantes sociais da saúde, priorizando contextos sócio-políticos de baixa renda;

III - fomentar debate social amplo e atuar para que o Poder Público, as organizações da sociedade civil e agências internacionais relacionadas implementem políticas para intervir sobre os determinantes sociais que condicionam o nível de saúde; e

IV - elaborar programa de ação a médio e longo prazo para incorporar as suas recomendações às políticas, planos e programas relacionados com a saúde, bem como para promover a sua implementação no âmbito da União, dos Estados, do Distrito Federal e dos Municípios.

Art. $4^{\circ}$ Para promover a articulação com as áreas de governo e prestar apoio técnico aos trabalhos da CNDSS, fica constituído Grupo de Trabalho, cujos membros serão designados pelo Ministro de Estado da Saúde, mediante indicação do respectivo representante pelos dirigentes máximos das seguintes instituições:

I - Casa Civil da Presidência da República;

II - Ministério da Saúde;

III - Ministério do Planejamento, Orçamento e Gestão;

IV - Ministério da Fazenda;

V - Ministério do Desenvolvimento Social e Combate à Fome;

VI - Ministério da Educação;

VII - Ministério da Ciência e Tecnologia;

VIII - Ministério da Cultura;

IX - Ministério do Esporte;

X - Ministério das Cidades;

XI - Ministério do Meio Ambiente;

XII - Ministério do Trabalho e Emprego;

XIII - Ministério da Previdência Social;

XIV - Ministério do Desenvolvimento Agrário;

XV - Secretaria Especial de Políticas de Promoção da Igualdade Racial da Presidência da República;

XVI - Secretaria Especial de Políticas para as Mulheres, da Presidência da República;

XVII - Conselho Nacional de Secretários de Saúde (Conass);

XVIII - Conselho Nacional de Secretários Municipais de Saúde (Conasems); e

XIX - Conselho Nacional de Saúde. 
Parágrafo único. A Organização Pan-Americana da Saúde no Brasil (Opas) poderá indicar representante para integrar o Grupo de Trabalho de que trata este artigo.

Art. $5^{\circ}$ A CNDSS, no prazo de até trinta dias após a sua primeira reunião, submeterá à aprovação do Ministro de Estado da Saúde proposta de seu regimento interno, que disporá sobre o seu funcionamento.

Art. $6^{\circ}$ Os serviços prestados pelos membros da CNDSS e do Grupo de Trabalho, considerados de relevante interesse público, não serão remunerados.

Art. $7^{\circ}$ A CNDSS terá prazo de dois anos para conclusão de seus trabalhos, com apresentação de relatório final ao Ministro de Estado da Saúde.

Art. $8^{\circ}$ Este Decreto entra em vigor na data de sua publicação.

Brasília, 13 de março de 2006; 1850 da Independência e 1180 da República.

LUIZ INÁCIO LULA DA SILVA

Saraiva Felipe 


\section{Anexo II A}

\section{PoRTARIA Ministerial nOMEANDO OS InTEGRANTES DA CNDSS}

PORTARIA No 532, DE 14 DE MARÇO DE 2006

O MINISTRO DE ESTADO DA SAÚDE, no uso das atribuições que lhe confere o art. 87, parágrafo único, inciso IV, da Constituição Federal, e tendo em vista o art. $2^{\circ}$ do Decreto de 13 de março de 2006, que institui, no âmbito do Ministério da Saúde, a Comissão Nacional sobre Determinantes Sociais da Saúde (CNDSS), resolve:

Art. $1^{\circ}$ Designar os membros da Comissão Nacional sobre Determinantes Sociais da Saúde (CNDSS) com a finalidade de apoiar e articular a atuação do Poder Público, as instituições de pesquisa e da sociedade civil sobre determinantes sociais relacionados à melhoria da saúde e à redução das iniqüidades sanitárias.

I - Paulo Marchiori Buss - Fundação Oswaldo Cruz - que o coordenará;

II - Adib Jatene - Academia Nacional de Medicina;

III - Aloísio Teixeira - Universidade Federal do Rio de Janeiro - UFRJ;

IV - Ana Lúcia Gazzola - Universidade Federal de Minas Gerais - UFMG;

V - César Victora - Universidade Federal de Pelotas - UFPel;

VI - Dalmo Dallari - Universidade de São Paulo - USP;

VII - Eduardo Eugênio Gouvêa Vieira - Federação das Indústrias do Estado do Rio de Janeiro - Firjan;

VIII - Elza Salvatori Berquó - Centro Brasileiro de Análise e Planejamento - Cebrap;

IX - Sérgio de Magalhães Gomes Jaguaripe (Jaguar) - cartunista;

X - Jairnilson Paim - Universidade Federal da Bahia - Ufba;

XI - Maria Lucélia dos Santos - Atriz;

XII - Moacyr Scliar - Academia Brasileira de Letras;

XIII - Roberto Smeraldi - Amigos da Terra Amazônia Brasileira;

XIV - Rubem César Fernandes - Movimento Viva Rio;

XV - Sandra de Sá - Cantora;

XVI - Sônia Fleury - Cientista Política Fundação Getúlio Vargas; e

XVII - Zilda Arns Neumann - Pastoral da Criança.

Art. $2^{\circ}$ Os serviços prestados pelos membros da CNDSS são considerados de relevante interesse público, e não serão remunerados.

Art. $3^{\circ}$ A CNDSS terá prazo de trinta dias, após sua primeira reunião, para apresentar a proposta do regimento interno que disporá sobre seu funcionamento.

Art. $4^{\circ}$ A CNDSS terá prazo de dois anos para conclusão de seus trabalhos, com apresentação de relatório final.

Art. $5^{\circ}$ Esta Portaria entra em vigor na data de sua publicação

\section{SARAIVA FELIPE}




\section{Anexo III}

\section{INIQÜIDADES EM SAÚDE NO BRASIL: NOSSA MAIS GRAVE DOENÇA ${ }^{1}$}

\section{Introdução}

As iniqüidades em saúde entre grupos e indivíduos, ou seja, as desigualdades de saúde que além de sistemáticas e relevantes são também evitáveis, injustas e desnecessárias, segundo a definição de Margareth Whitehead, são um dos traços mais marcantes da situação de saúde do Brasil. A mortalidade infantil, cuja média nacional é de 25 por mil nascidos-vivos (NV), apresenta grandes disparidades regionais, observando-se taxas inferiores a 10 por mil NV, em alguns municípios do Sul e Sudeste e valores maiores do que 50 por mil NV, em áreas do Nordeste. Segundo o relatório da Unicef, de junho 2003, sobre eqüidade na infância e adolescência no Brasil, a taxa de mortalidade em menores de 5 anos (TMM5), em 1999, era de 57,4 por mil nascidos vivos, variando de 81,6 para o quintil de renda mais baixo a 29,8 para o mais alto. De acordo com a escolaridade da mãe, a TMM5 variava de 93 para mães com menos de 4 anos de estudo a 30,4 para aquelas com mais de 8 anos de estudo. O filho de uma mulher com até um ano de escolaridade tem uma probabilidade 23 vezes maior de chegar analfabeto à adolescência, se comparado com o filho de uma mulher com 11 anos de estudo.

Há muito se reconhece que os principais determinantes dessas iniqüidades estão relacionados às formas como se organiza a vida social. Já em meados do século XIX, Virchow entendia que a "ciência médica é intrínseca e essencialmente uma ciência social", que as condições econômicas e sociais exercem um efeito importante sobre a saúde e a doença e que tais relações devem submeterse à pesquisa científica. Entendia também que o próprio termo "saúde pública" expressa seu caráter político e que sua prática deve conduzir necessariamente à intervenção na vida política e social para indicar e eliminar os obstáculos que dificultam a saúde da população.

Desde então muito se avançou na construção de modelos explicativos que analisam as relações entre a forma como se organiza e se desenvolve uma determinada sociedade e a situação de saúde de sua população. Um dos principais desafios destes modelos explicativos é o estabelecimento de uma hierarquia de determinações entre os fatores mais globais de natureza social, econômica, política e as mediações através das quais estes fatores incidem sobre a situação de saúde de grupos e pessoas. É este complexo de mediações que permite entender porque não há uma correlação constante entre os macro-indicadores da riqueza de uma sociedade, como o Produto Interno Bruto (PIB), com os indicadores de saúde. Evidentemente, o volume de riqueza gerado por uma sociedade é um elemento fundamental para proporcionar melhores condições de vida e de saúde, mas há inúmeros exemplos de países com PIB total ou PIB per capita bem superior a outros que, apesar disso, possuem indicadores de saúde muito mais satisfatórios.

Nos últimos anos, aumentaram também, em quantidade e qualidade, os estudos sobre as relações entre a saúde das populações, as desigualdades nas condições de vida e o grau de desenvolvimento da trama de vínculos e associações entre indivíduos e grupos. Estes estudos permitem constatar que, uma vez superado determinado limite de crescimento econômico de um país, um crescimento 
adicional da riqueza não se traduz em melhorias significativas das condições de saúde. A partir desse nível, o fator mais importante para explicar a situação geral de saúde de um país não é sua riqueza total, mas a maneira como ela se distribui.

Em outras palavras, a desigualdade na distribuição de renda não é prejudicial à saúde somente dos grupos mais pobres, mas é também prejudicial para a saúde da sociedade em seu conjunto. Grupos de renda média em um país com alto grau de iniqüidade de renda possuem uma situação de saúde pior do que a de grupos com renda inferior, mas que vivem em uma sociedade mais eqüitativa. Um estudo comparativo entre os estados dos Estados Unidos da América revelou que os indivíduos que vivem em estados com grandes diferenças de renda possuem pior saúde do que aqueles com ingressos equivalentes, mas que vivem em estados mais igualitários. o Japão não é o país com maior expectativa de vida do mundo por ser o país mais rico ou porque os japoneses fumam menos ou fazem mais exercício, mas porque é um dos países mais igualitários do mundo.

Estudos vêm demonstrando que o principal mecanismo através do qual as iniqüidades de renda produzem um impacto negativo na situação de saúde é o desgaste do chamado capital social, ou seja, das relações de solidariedade e confiança entre pessoas e grupos. Segundo vários autores, o desgaste do capital social em sociedades ineqüitativas explicaria, em grande medida, porque sua situação de saúde é inferior a de sociedades onde as relações de solidariedade são mais desenvolvidas. A debilidade dos laços de coesão social, ocasionada pelas iniqüidades de renda, corresponde a baixos níveis de capital social e de participação política. Países com grandes iniqüidades de renda, escassos níveis de coesão social e baixa participação política são os que menos investem em capital humano e em redes de apoio social, que são fundamentais para a promoção e proteção da saúde individual e coletiva.

No caso do Brasil, o fardo é duplo, pois além de apresentar graves iniqüidades na distribuição da riqueza, há grandes setores de sua população vivendo em situação de pobreza que não lhes permite ter acesso a mínimas condições e bens essenciais à saúde. Além da renda dos $20 \%$ mais ricos ser 26 vezes maior do que a renda dos $20 \%$ mais pobres, $24 \%$ da população economicamente ativa possuem rendimentos menores que 2 dólares por dia. 0 tema da pobreza também vem chamando a atenção de muitos autores, o que vem gerando uma mudança na maneira como a entendemos e nas formas para combatê-la. Para estes autores, a pobreza não é somente a falta de acesso a bens materiais, mas é também a falta de oportunidades e de possibilidades de opção entre diferentes alternativas. Pobreza é, também, a falta de voz frente às instituições do Estado e da sociedade e uma grande vulnerabilidade frente a imprevistos. Nesta situação a capacidade dos pobres de atuar em favor de sua saúde e da coletividade está bastante diminuída.

Para ser coerente com esta nova maneira de entender a pobreza, as estratégias para combatêla devem incluir tanto a geração de oportunidades econômicas, como medidas que favoreçam a construção de redes de apoio e o aumento das capacidades desses grupos para conhecer melhor os problemas locais e globais, para estreitar suas relações com outros grupos, para fortalecer sua organização e participação em ações coletivas, para constituir-se, enfim, em atores sociais e ativos participantes das decisões da vida social.

Infelizmente, estes e outros importantes avanços no conhecimento dos determinantes sociais das condições de saúde e, em particular, das iniqüidades em saúde, encontrados na literatura científica 
brasileira e internacional, não são acompanhados por um correspondente avanço na utilização desse conhecimento para a definição de políticas de saúde no país.

Isto se deve, em grande medida, à debilidade das relações entre o processo de produção do conhecimento e o processo de tomada de decisão sobre políticas e programas de saúde, o qual deveria basear-se em conhecimentos e evidências. Ambos os processos costumam desenvolver-se por separado, com lógicas, agentes e espaços institucionais específicos. Por outro lado, a aproximação entre pesquisa em saúde e políticas de saúde com vistas à promoção da eqüidade não significa a despolitização das decisões sobre políticas em nome de uma racionalidade centralizadora baseada em evidência científica.

Em geral, não há prescrições categóricas de políticas baseadas em resultados objetivos de pesquisas, mas um leque de opções que a ciência ajuda a delimitar. A seleção entre estas opções se faz por meio de um processo que é essencialmente político, envolvendo diversos atores, com interesses diferenciados e eventualmente contraditórios. Para que haja maior utilização de resultados de investigação para a definição de políticas, é necessário instrumentalizar a atuação desses diferentes atores, particularmente dos que usualmente estão excluídos do processo de decisão, buscando diminuir as enormes iniqüidades de acesso a informações e conhecimentos.

Não há, portanto nenhuma contradição entre, por um lado, a promoção de políticas baseadas em evidência e, por outro, a ampliação da participação social na definição das mesmas. Na realidade, para que as políticas de saúde se consolidem como políticas públicas voltadas a atender ao interesse público e à promoção da eqüidade, é necessário o fortalecimento do processo democrático de definição destas políticas, multiplicando os atores envolvidos, os espaços e oportunidades de interação entre eles e instrumentalizando sua participação com o acesso eqüitativo a informações e conhecimentos pertinentes.

\section{A Comissão Nacional de Determinantes Sociais em Saúde - CNDSS}

Preocupado com as iniqüidades que se verificam nas condições de saúde da população e no acesso aos serviços de saúde e a outros serviços públicos que influenciam a situação de saúde, o governo brasileiro decidiu criar a Comissão Nacional sobre Determinantes Sociais da Saúde (CNDSS), no bojo de um movimento mundial em torno deste tema, proposto pela Organização Mundial da Saúde (OMS).

Na Assembléia Mundial da Saúde de 2004, o então Diretor Geral da OMS, Lee Jong-Wook, propôs a criação de uma comissão para recomendar políticas públicas de saúde e externas ao setor, assim como intervenções que visem a melhoria das condições de saúde e a diminuição das iniqüidades. A Comissão sobre Determinantes Sociais da Saúde (CSDH-OMS) foi criada em março de 2005, com vigência de 3 anos.

A CSDH-OMS é um fórum estratégico mundial formado por lideranças políticas, científicas e da sociedade civil organizada. A Comissão tem como meta global a busca de eqüidade em saúde. Lidera um processo mundial de organização do conhecimento sobre os determinantes sociais em saúde, com vistas a fortalecer as práticas e as políticas voltadas para a diminuição das iniqüidades. 
Entre os objetivos da CSDH-OMS, merecem destaque:

- a sistematização de evidências sobre experiências e formulação de políticas que enfocam os determinantes sociais em saúde;

- o fomento do debate junto à sociedade, para a implantação de ações de enfrentamento dos determinantes sociais em saúde;

- a definição de compromissos de médio e longo prazo, com vistas a incorporar as desigualdades em saúde como tema central da agenda da OMS.

Em julho de 2005, a Organização Pan-americana da Saúde (Opas) reuniu, em Washington, os países da região das Américas e apresentou a proposta da CSDH-OMS, despertando o interesse dos países sobre a temática. Após essa reunião, a Fundação Oswaldo Cruz (Fiocruz) e a Secretaria de Vigilância em Saúde (SVS), do Ministério da Saúde, lideraram o processo para a definição de uma agenda de atividades no Brasil, buscando respostas sociais organizadas para o enfrentamento dos determinantes sociais em saúde no país.

Em março de 2006, ao completar tão somente um ano da criação da Comissão mundial, apressa-se o Brasil a participar desta iniciativa, com o lançamento da Comissão Nacional sobre Determinantes Sociais da Saúde (CNDSS) no país.

A CNDSS é fruto de um processo de construção da Reforma Sanitária, que já dura pelo menos quatro décadas, e que teve como um de seus pontos culminantes a incorporação pela Constituição Federal do Brasil, aprovada em 1988, do artigo 196, determinando que "a saúde é direito de todos e dever do Estado, garantido mediante políticas sociais e econômicas que visem à redução do risco de doença e de outros agravos e ao acesso universal e igualitário às ações e serviços para sua promoção, proteção e recuperação".

Apesar deste e de outros avanços alcançados nas últimas décadas, constatados pela melhoria de alguns índices de desenvolvimento social e pela criação do Sistema Único de Saúde (SUS), com base nos princípios de solidariedade e universalidade da assistência, grandes parcelas da população brasileira ainda sofrem problemas geradores de importantes iniqüidades em saúde, como o desemprego, a falta de acesso à moradia digna, ao sistema de saneamento básico, a serviços de saúde e de educação de qualidade e a um meio ambiente protegido.

o monitoramento dessas iniqüidades e o estudo sistemático e aprofundado de seus determinantes deverão permitir identificar pontos mais vulneráveis ao impacto de políticas públicas que buscam combatê-las. Para que essas políticas sejam mais efetivas, é necessário, portanto, por um lado, aumentar os conhecimentos sobre determinantes sociais em saúde, suas hierarquias e mediações e, por outro lado, facilitar a incorporação desses conhecimentos na definição e implantação das políticas. São estes os mais importantes desafios que a CNDSS se propõe a enfrentar, com vistas a colaborar na construção de uma sociedade mais justa, igualitária e humana.

Serão suas principais linhas de atuação:

- estimular a melhoria da qualidade e completude das informações sociodemográficas nos sistemas de informação oficiais da saúde, de forma a permitir o monitoramento das desigualdades sociais em saúde; 
- introduzir a temática dos determinantes sociais da saúde e das conseqüências das desigualdades na formação dos profissionais de saúde;

- fomentar e mobilizar os profissionais e gestores de saúde em prol de políticas públicas focadas, explicitamente, na busca da eqüidade em saúde;

- mobilizar a sociedade civil para a defesa do princípio da eqüidade na execução das políticas públicas pertinentes;

- criar instrumentos que possibilitem a circulação, na sociedade, dos conhecimentos e direitos relativos aos determinantes sociais da saúde;

- criar fóruns intersetoriais para o debate do tema e estabelecimento de compromissos pactuados de enfrentamento do problema, incluindo a discussão de modelos de políticas de curto, médio e longo prazo;

- estimular a produção de conhecimentos sobre os determinantes sociais em saúde através de linhas específicas de financiamento à pesquisa e de apoio à formação de investigadores;

- incluir metas para redução das desigualdades sociais em saúde, de maneira explícita, nas políticas sociais;

- articular-se com outras iniciativas de políticas públicas de redução da pobreza e de riscos à saúde, a exemplo do Conselho Nacional de Desenvolvimento Econômico e Social (CNDES), Fome Zero, Conselho Nacional de Segurança Alimentar (Consea) e outros;

- promover a defesa e indução de ações para o enfrentamento das desigualdades sociais em saúde, no Brasil, junto as três esferas de governo, nos âmbitos executivo e legislativo;

- garantir a inclusão e a execução, refletidas nos orçamentos públicos das três esferas de governo, de ações dirigidas à redução das iniqüidades em saúde. 


\section{Anexo III A}

Discurso proferido pelo Dr. Adib Jatene na cerimônia de entrega do relatório da CNDSS ao Exmo. Presidente da República em $1^{\circ}$ agosto de 2008

Os membros da Comissão sobre Determinantes Sociais da Saúde entregam neste ato o relatório final do seu trabalho intitulado "Causas Sociais das Iniqüidades em Saúde no Brasil".

Nossa Comissão foi criada por V. Exa . em atendimento e recomendação da Organização Mundial da Saúde de março de 2005. Estamos entre os primeiros países que acolheram a recomendação baseada em que a saúde é um fenômeno social, ou seja, são as condições de vida e trabalho os principais responsáveis pela saúde das pessoas e das comunidades.

O Brasil possui características peculiares por ter ingressado no desenvolvimento industrial e tecnológico com mais de 200 anos de atraso, o que resultou em urbanização acelerada com ênfase no desenvolvimento econômico e desprezo pelo desenvolvimento social. Isso gerou desigualdade social e concentração escandalosa de renda e de conhecimento em parcela minoritária da população. Nossa Comissão buscou elaborar o relatório dentro da tradição do movimento sanitário brasileiro exprimindo o reconhecimento de que saúde é um bem público construído com a participação solidária de todos os setores da sociedade brasileira.

O relatório procurou atender a três compromissos básicos.

o primeiro deles é o compromisso com a eqüidade. As iniqüidades em saúde são moralmente indefensáveis e seu combate é imperativo obrigando a intervenção sobre os determinantes que os geraram e que, sendo produto de ação humana equivocada, podem e devem ser transformados pela ação humana. É um comportamento eminentemente ético.

O segundo é o compromisso com a ação que implica elaborar recomendações concretas de políticas, programas e intervenções capazes de combater e corrigir as iniqüidades ora existentes. Essas intervenções exigem uma sólida base de apoio político que associa a lucidez da tomada e posições administrativas com um despertar da consciência dos diversos setores da população sobre a gravidade do problema das iniqüidades em saúde e sobre a urgente necessidade de combatê-las.

Já se vão 30 anos desde que a Organização Mundial da Saúde cunhou na sua Assembléia Geral em Alma-Ata o slogan "Saúde para todos no ano 2000" e em 2008 ainda assistimos, estarrecidos, ao grande descompasso entre o extraordinário desenvolvimento econômico e tecnológico ao lado de um subdesenvolvimento social mesmo em países desenvolvidos. Parece que o que conta são as coisas que as pessoas têm e não as pessoas.

O terceiro compromisso é com a evidência. As recomendações da Comissão estão solidamente fundamentadas em evidências científicas que permitem entender como operam os DSS na geração das iniqüidades e como e onde devem incidir as intervenções para combatê-las. Graças aos sistemas de informação de abrangência nacional, hoje disponíveis, bem como a quantidade e qualidade da produção científica nacional e internacional sobre o tema foi possível reunir sólidas evidências sobre o impacto dos diversos determinantes sociais na atual situação da saúde do país, em particular na geração das iniqüidades. 
Nosso relatório registra também os importantes avanços na situação de saúde dos brasileiros. Apenas dois exemplos: em 1960, a expectativa de vida de um brasileiro, na região Nordeste era de 49 anos, enquanto na Região Sul era de 69 anos. Em 2006, a expectativa de vida no Nordeste subiu para 69,5, enquanto no sul subia para 74,5 anos. A diferença de 20 anos reduziu-se para cinco anos. A proporção de óbitos de menores de um ano sobre o total de óbitos reduziu-se de $24 \%$, em 1980, para 5\% em 2005.

Ao lado de inegáveis avanços, nosso relatório aponta também os importantes desafios que todos temos de enfrentar para atender as metas de um país que colocou na sua Constituição que: "saúde é direito de todos, e dever do Estado", devendo ser oferecido com eqüidade e integralidade para todos.

Gostaria, antes de terminar, enfatizar que o trabalho da Comissão Nacional foi facilitado pela participação de diversas instituições, em particular da Fiocruz, que sediou a Secretaria Técnica da Comissão coordenada, magnificamente por Alberto Pellegrini Filho, a quem todos, por meu intermédio, agradecem.

Devo ressaltar o apoio político dos mais altos escalóes do governo, principalmente dos ministros da Saúde, Saraiva Felipe, Agenor Álvares e José Gomes Temporão. O ministro Temporão tem sido um batalhador incansável, para que o Ministério da Saúde seja efetivamente voltado para a promoção de saúde e bem-estar da população, e não apenas um Ministério da doença.

Em nome dos demais membros da Comissão gostaria de agradecer a oportunidade que nos foi dada de, modestamente, contribuir para que nossa sociedade seja cada vez mais humana e justa, e que nos permita conquistar segurança e paz. 